\title{
In memoriam Esther Fischer-Homberger (1940-2019)
}

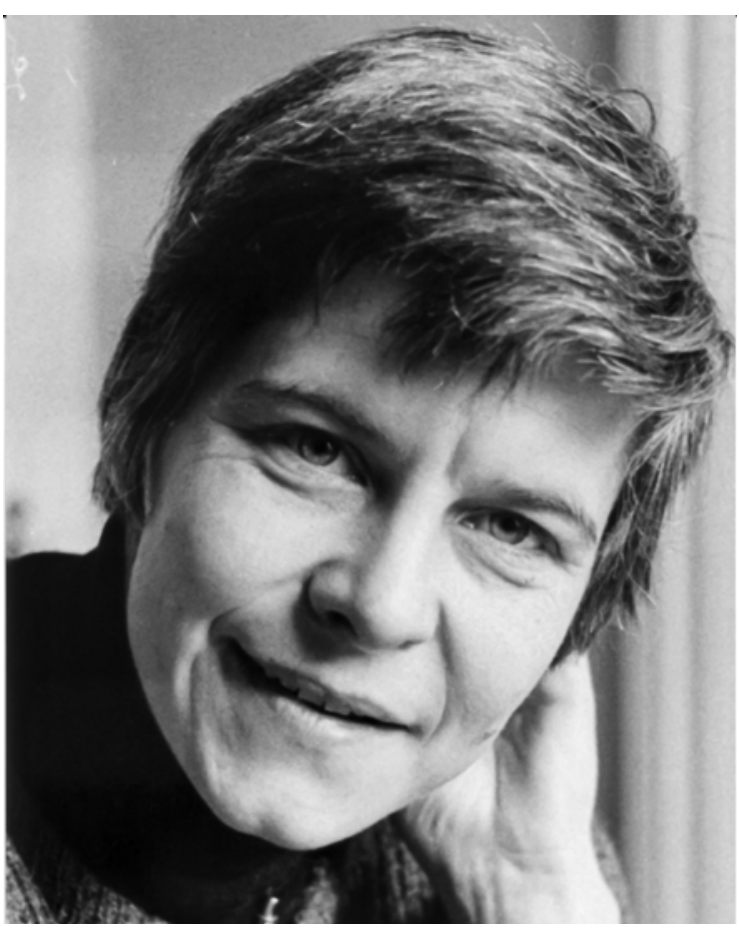

Esther Fischer-Homberger

\section{Die Frei-Denkerin}

Die Berner Pionierin der Medizin- und Geschlechtergeschichte ist gestorben. Ein Nachruf auf Esther FischerHomberger.

Heute spricht man vom «Bikini-Blick». Die Tageszeitungen berichten erstaunt über den statistisch nachgewiesenen Effekt, dass Leiden von Männern eher ernst genommen und diese auf dem Notfall schneller behandelt werden. Bei Frauen achtet die Medizin vor allem auf die spezifischen Frauenkrankheiten; andere Symptome wie chronische Schmerzen oder Migräne werden oft vorschnell als typisch weibliche, hormonell oder psychisch bedingte Leiden abgehakt.

Korrespondenz:

Prof. Dr. med.

Dr. phil. Hubert Steinke Institut für Medizin-

geschichte

Bühlstrasse 26

Postfach

CH-3000 Bern 9

Tel. 0316318429

hubert.steinke[at]

img.unibe.ch
Man könnte auch von der "Krankheit Frau» sprechen und damit den Titel eines Buchs verwenden, das Esther Fischer-Homberger vor 40 Jahren veröffentlichte. In einer Zeit, als die Medizingeschichte noch stark mit den Erfolgen grosser Männer beschäftigt war und sich die Geschlechtergeschichte hierzulande erst langsam entwickelte, untersuchte sie den männlichen Blick auf den weiblichen Körper. Sie legte dar, wie Nervosität, Hypochondrie, Hysterie und Menstruation als Krankheiten konstruiert wurden, die dem weiblichen Körper eingeschrieben sind. Auch wenn Fischer-Homberger dezidiert kritisch-historisch argumentierte, so waren ihre flüssigen Texte immer auch als Beitrag zu aktuellen Debatten zu lesen. Wer sich für den «Bikini-Blick» interessiert, wird ihr Buch auch heute noch mit Gewinn lesen.

Esther Fischer-Homberger wurde 1940 geboren, studierte in Zürich Medizin, habilitierte sich dort in Medizingeschichte und wurde 1978 als Professorin für Medizingeschichte nach Bern berufen. Sie baute ein kleines Institut auf, forschte erfolgreich nicht nur zum Frauenkörper, sondern auch zur Gerichtsmedizin und Psychiatriegeschichte, äusserte sich öffentlich in Vorträgen und Interviews - und trat 1984 von ihrem Amt zurück. Sie begründete ihren Entscheid mit mangelndem Raum für schöpferische Arbeit, Verzettelung, "Ausstech- und Turniermethoden zur Entscheidung fachlicher Fragen" und Normen und Werten, die sie nur teilweise zu den ihrigen machen konnte. Die von Kollegen geäusserte Kritik der Verantwortungslosigkeit und Unberechenbarkeit von Frauen konterte sie mit der Bemerkung, es wäre erfrischend, wenn mehr Professoren, die ihren Elan und Erfindungsgeist verloren haben, zurücktreten würden, statt nur noch auf die Pensionierung zu warten. Fischer-Homberger kehrte zu ihrer «alten Liebe», der Psychiatrie, zurück und war daneben - im Austausch mit, aber ohne Einengung durch die Universität - bis zuletzt auch medizinhistorisch tätig.

Frischen Wind versuchte sie als Berner Grossrätin der Freien Liste (1984-1990) auch in die politische Diskussion zu bringen: Sie schlug tägliches Durchlüften, bunte Kostüme für verschiedene Fraktionen oder Lügenverbote vor - und natürlich viele ernstere Programme. Im Rat konstatierte sie Polarisierung, mangelnde Differenziertheit und Tiefe der Diskussion.

Esther Fischer-Homberger war verheiratet mit dem Schauspieler Kaspar Fischer und lebte seit 1984 mit der Autorin Marie-Luise Könneker. Sie ist am 21. März in Bern verstorben.

Hubert Steinke,

Prof. Dr. med. Dr. phil., Institut für Medizingeschichte, Universität Bern 